\title{
Perancangan dan Pembuatan Aplikasi Permainan Nusantara Indonesia Berbasis Android
}

\author{
Claudia Agustina Hartono \\ Program Studi Teknik Informatika \\ Institut Informatika Indonesia \\ diathedia@yahoo.co.id
}

\author{
Hermawan Andika \\ Program Studi Teknik Informatika \\ Institut Informatika Indonesia \\ andi@ikado.ac.id
}

\author{
Edwin Meinardi Trianto \\ Program Studi Manajemen \\ Informatika \\ Institut Informatika Indonesia \\ edwin@ikado.ac.id
}

\begin{abstract}
Abstrak-Game atau yang biasa disebut permainan merupakan aktivitas terstruktur atau semi terstruktur yang biasanya bertujuan untuk menghibur. Penulis mengembangkan suatu permainan berbasis android dengan judul "Nusantara Indonesia" dengan tujuan mengenalkan budaya di Indonesia yang semakin hilang. Pengembangan permainan ini menggunakan framework Starling dan aplikasi Adobe Flash Builder. Beberapa fitur dalam permainan ini adalah fitur touch, swipe, dan gyro yang membuat permainan menjadi menarik untuk dimainkan. Terdapat pula cerita yang berperan sebagai media informasi mengenai budaya Indonesia.
\end{abstract}

Kata Kunci : Game, Android, Starling, Gyroscope, Nusantara Indonesia

\section{PENDAHULUAN}

Dalam era globalisasi ini, media buku yang digunakan untuk pembelajaran kini ditinggalkan, digantikan dengan media komputer atau smartphone dan internet. Namun, dalam internet yang begitu luas, terkadang informasi mengenai budaya dan sejarah tertinggal karena dinilai tidak menarik. Agar nilai-nilai budaya Indonesia tidak hilang, inovasi dan metode pengajaran yang baru dan tepat menggunakan media yang digemari dibutuhkan. Media tersebut adalah aplikasi game atau permainan. Game adalah salah satu media yang paling digemari pada era globalisasi. Dalam permainan "Nusantara Indonesia" terdapat unsur cerita budaya sehingga pemain dapat belajar mengenai budaya sambil bermain. Didasari latar belakang tersebut, penulis tertarik untuk mendalami pembuatan permainan dan diwujudkan dengan perancangan dan pembuatan permainan

"Nusantara Indonesia" berbasis android.

\section{METODOLOGI PENELITIAN}

Telah diketahui pada pendahuluan bahwa terdapat beberapa hal yang berperan penting dalam pembuatan aplikasi "Nusantara Indonesia" berbasis android. Hal-hal tersebut akan dijabarkan pada sub-bab dibawah ini:

\section{A. Kebudayaan Indonesia}

Indonesia memiliki sekitar 300 kelompok etnis, tiap etnis memiliki warisan budaya yang berkembang selama berabadabad, dipengaruhi oleh kebudayaan India, Arab, Tiongkok, Eropa, dan Melayu [1]. Kebudayaan Indonesia meliputi tarian, pantun, gurindam, wayang, hingga permainan tradisional. Beberapa kebudayaan akan dibahas oleh penulis dalam permainan "Nusantara Indonesia". Lima permainan tradisional yang akan diaplikasikan oleh penulis adalah Bekelan, Gobag Sodor, Congklak, Balap Karung, dan Tilako.

\section{B. Android}

Android adalah sistem operasi untuk telepon seluler yang berbasis Linux. Android menyediakan platform terbuka bagi para pengembang untuk menciptakan aplikasi mereka sendiri untuk digunakan oleh bermacam piranti bergerak. Android begitu pesat perkembangannya di era saat ini karena Android menyediakan platform terbuka (open source) bagi para pengembang untuk menciptakan aplikasi mereka sendiri.

Perkembangan yang pesat pada sistem Android karena juga didukung oleh hampir keseluruhan vendor smartphone. hal ini karena sifatnya yang open source sehingga siapa saja bisa mengembangkan OS tersebut untuk digunakan pada perangkat mereka dan disesuaikan dengan kebutuhan dan pasar. Seperti pada distribusi Linux yang sering berkembang demikian juga dengan Android itu sendiri sejak awal dikembangkan 2009 sampai sekarang sudah memiliki 5 versi dan akan terus berkembang karena pasar yang semakin melirik OS ini dan mudahnya pengembangan.

Android SDK merupakan sebuah tool yang diperlukan untuk mengembangkan aplikasi berbasis Android menggunakan bahasa pemrograman Java. Pada saat ini Android SDK telah menjadi alat bantu dan API (Application Programming Interface) untuk mengembangkan aplikasi bebasis Android. Android SDK dapat Anda lihat dan unduh pada situs resminya, yaitu http://www.developer.android.com/. Android SDK bersifat gratis dan bebas untuk distribusikan karena Android bersifat open source. 


\section{Starling}

Starling adalah ActionScript 3 library untuk Adobe Flash. Starling dapat menggambar tampilan Adobe Flash pada GPU dan memberikan performa yang luar biasa bahkan pada platform Mobile, seperti iOS dan Android [2].

Selain bahasa, starling tidak memerlukan pengetahuan tentang dasar Flash (ActionScript 3). Starling memulai penjelasan dari awal, dimulai dengan cara mengatur proyek, kemudian menjelaskan bagaimana pohon display dan sistem event bekerja, dan menunjukkan kepada anda bagaimana untuk mencapai tugas-tugas tertentu.

\section{Adobe Flash Builder}

Mulyadi menjelaskan "Adobe Flash Builder - sebuah lingkungan pengembangan terintegrasi untuk menciptakan aplikasi cross-platform [3]. Adobe Flash Builder membuat aplikasi yang menggunakan infrastruktur Adobe Flex, MXML, Adobe Flash Player, Adobe AIR, ActionScript 3.0, Adobe LiveCycle ES Layanan Data komponen dan Adobe Flex Charting" (hal.69). Adobe Flash Builder juga termasuk alat untuk pengujian, debugging dan profiling, yang dicapai melalui peningkatan produktivitas dan efisiensi.

\section{HASIL DAN PEMBAHASAN}

Agar pengembangan aplikasi lebih maksimal, melakukan analisa terhadap aplikasi sangat penting, sehingga sistem yang akan dibangun memiliki acuan dan gambaran umum.

\section{A. Use Case Diagram}

Suhendar A. mengatakan "Use Case Diagram menjelaskan urutan kegiatan yang dilakukan aktor dan sistem untuk mencapai tujuan tertentu, menggambarkan fungsionalitas yang diharapkan dari sebuah sistem." [4] Use case diagram juga serta mempresentasikan interaksi antar aktor/pelaku dengan sistem. Untuk gambaran lebih jelas dapat dilihat pada gambar use case diagram berikut:

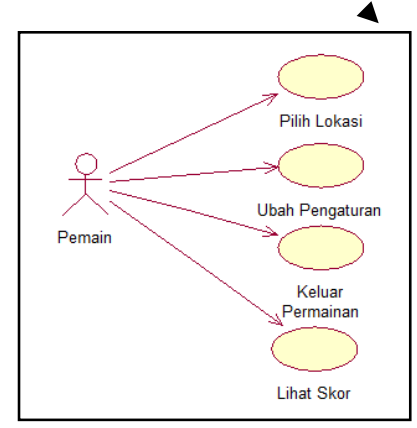

Gambar 1. Use Case Diagram Permainan

Dari use case diagram diatas, dapat dilihat interaksi yang terjadi dalam permainan "Nusantara Indonesia", antara lain pilih lokasi, ubah pengaturan, keluar permainan, dan lihat skor.

\section{B. Activity Diagram}

Suhendar A. mengatakan "Activity diagram adalah representasi grafis dari seluruh tahapan alur kerja. Diagram ini mengandung aktivitas, pilihan tindakan, perulangan dan hasil dari aktivitas."[4] Berikut adalah activity diagram dari tiap permainan:

\section{a) Activity Diagram Bekelan}

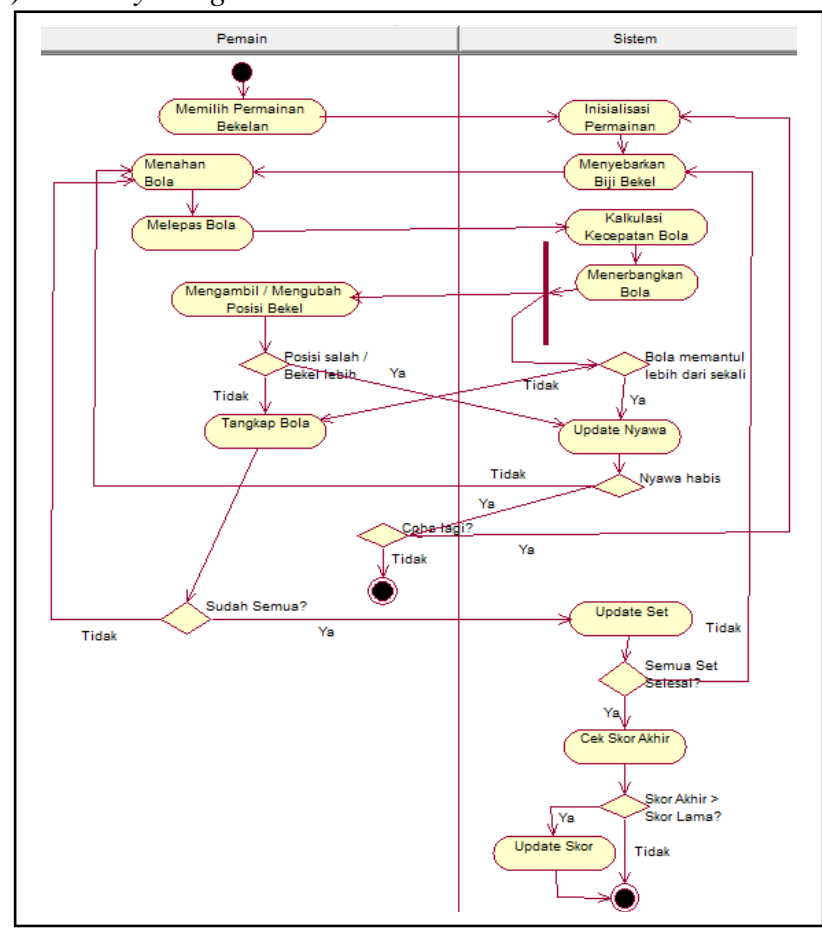

Gambar 2. Activity Diagram Bekelan

b) Activity Diagram Gobag Sodor

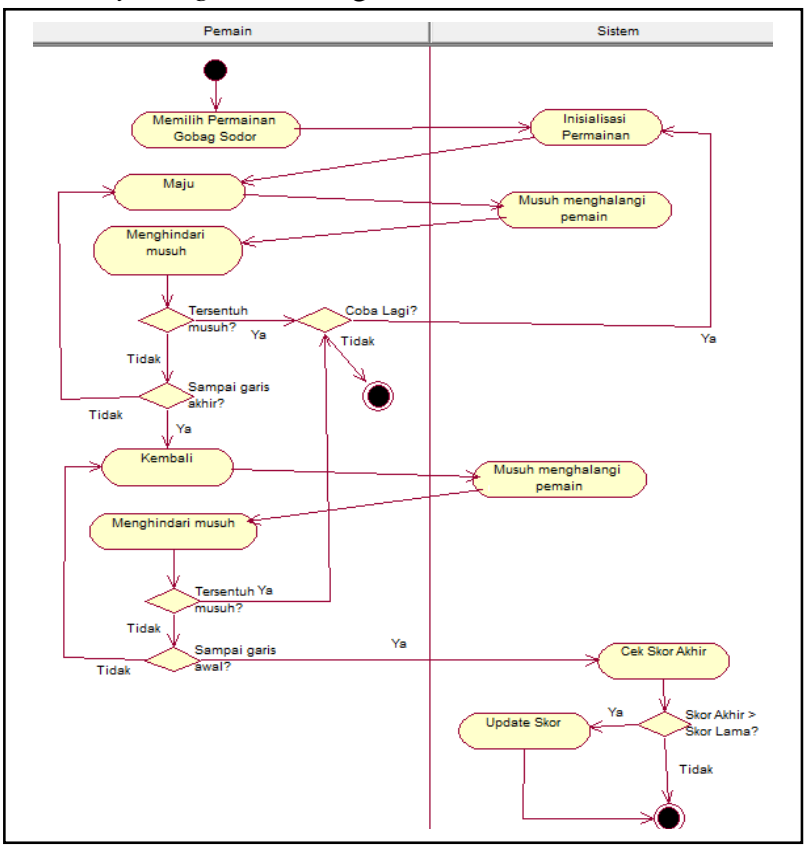

Gambar 3. Activity Diagram Gobag Sodor 
c) Activity Diagram Congklak

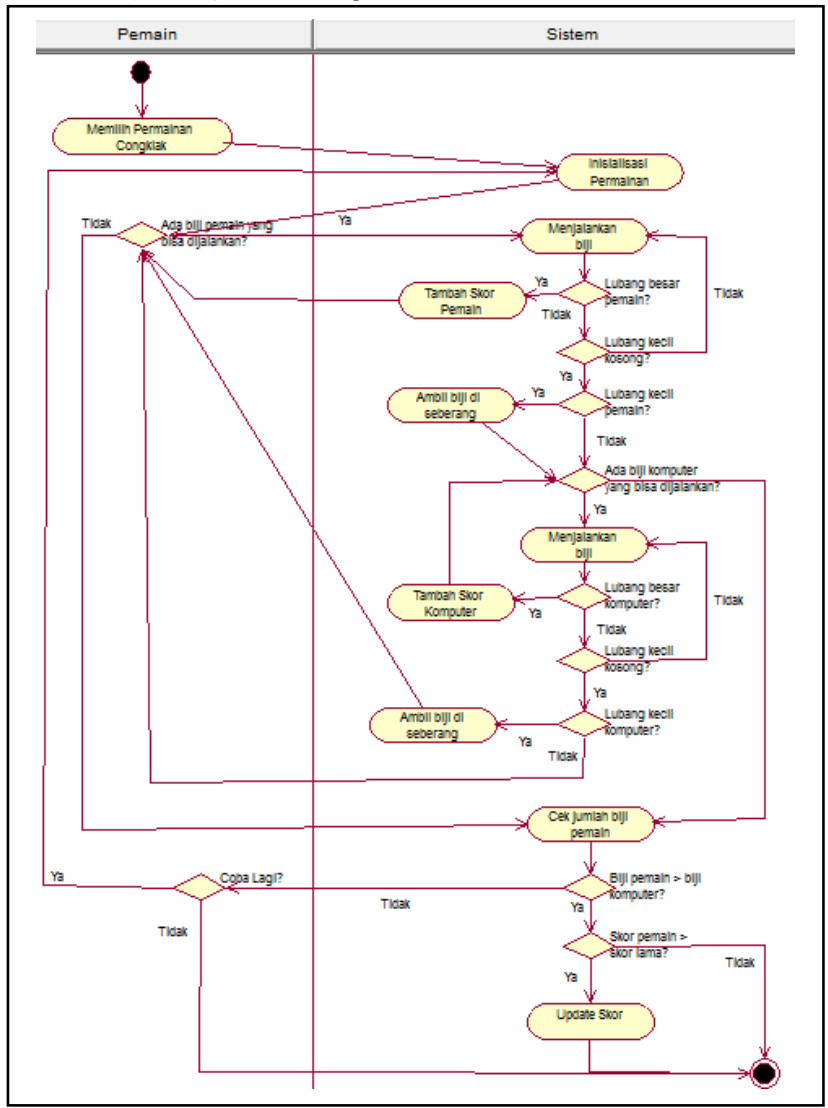

Gambar 4. Activity Diagram Congklak

d) Activity Diagram Balap Karung

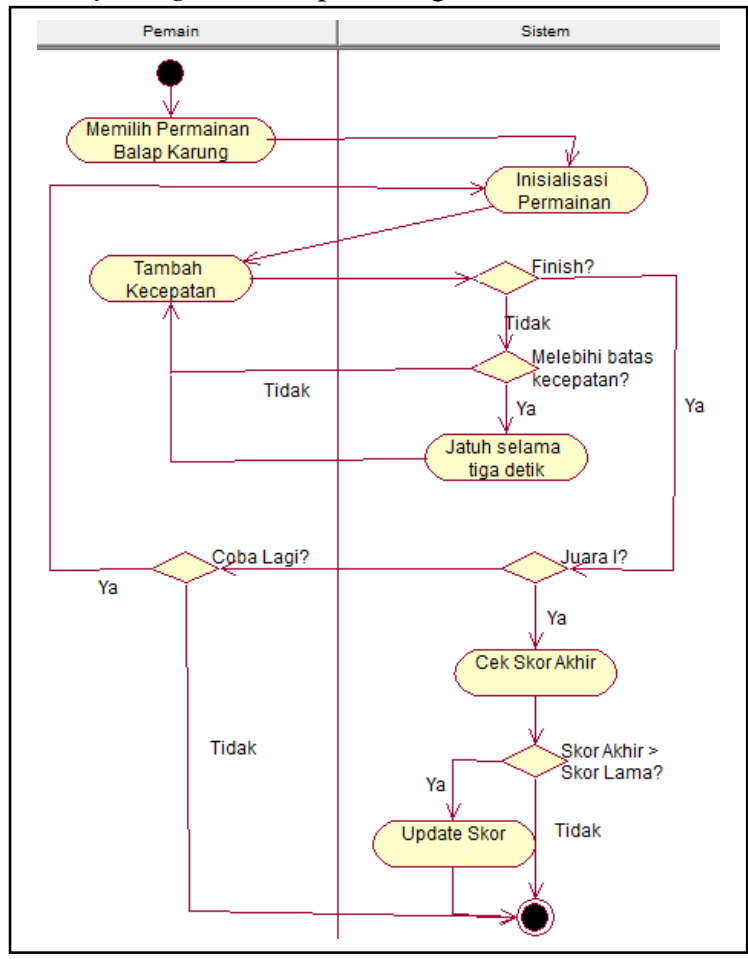

Gambar 5. Activity Diagram Balap Karung e) Activity Diagram Tilako

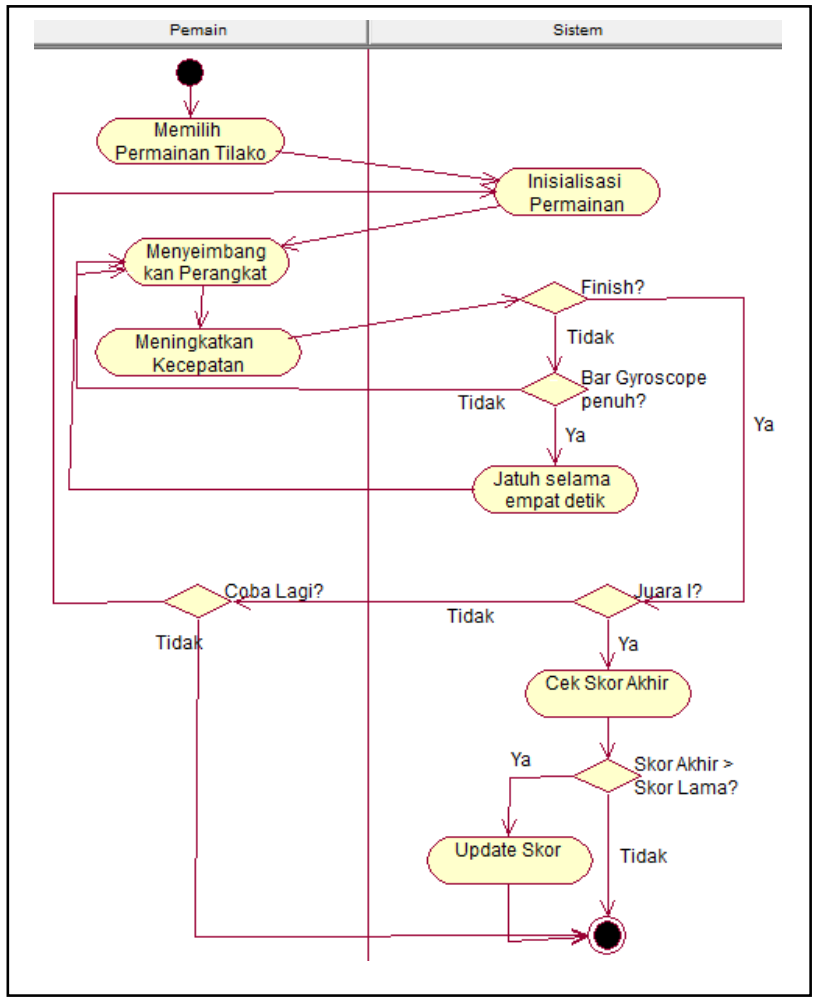

Gambar 6. Activity Diagram Tilako

\section{User Interface}

Pada sub bab ini akan ditunjukkan tampilan antar muka dari permainan "Nusantara Indonesia" yang nantinya akan berinteraksi dengan user.

- Menu Utama

Merupakan menu awal dalam permainan. Di dalam menu ini terdapat 3 buah tombol yaitu tombol Mulai, Pengaturan, dan Tentang yang mengarah ke menu lainnya.

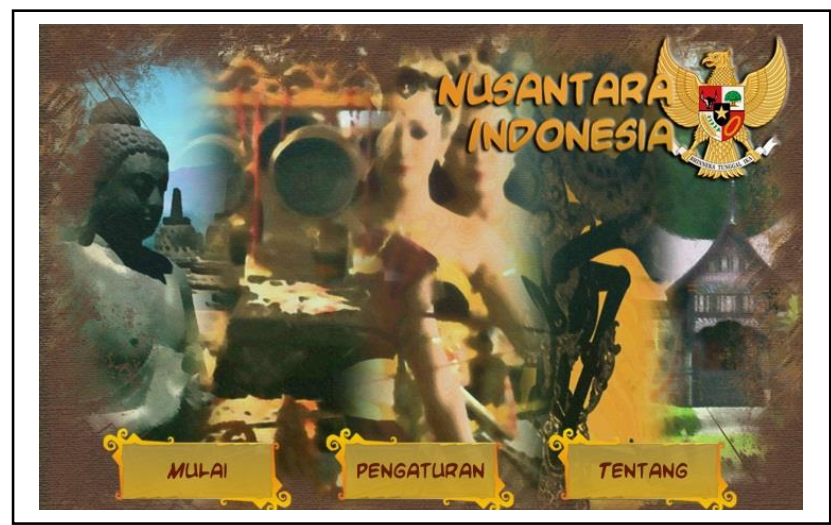

Gambar 7. Menu Utama 
- Menu Peta

Menu Peta berisikan lokasi-lokasi yang dapat dikunjungi oleh pemain, tombol pengaturan dan tombol skor yang digunakan untuk membuka halaman skor.

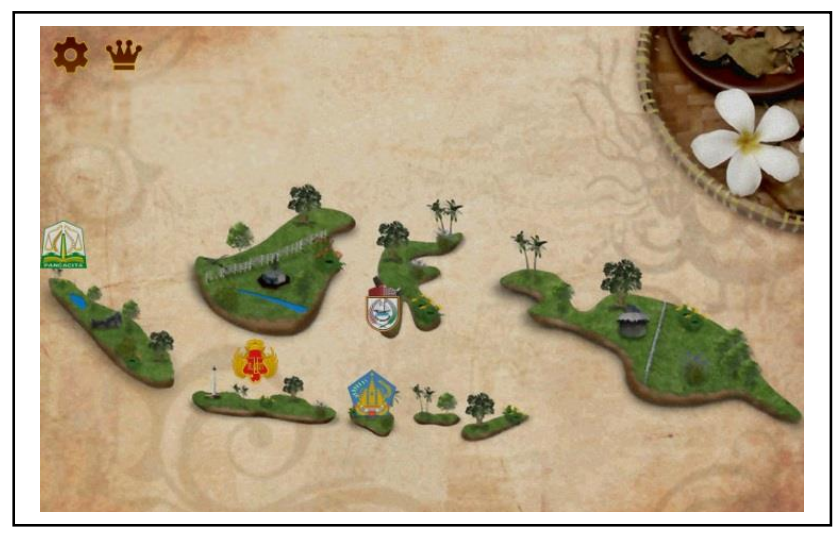

Gambar 8. Menu Peta

- Halaman Skor

Halaman Skor berisikan skor tertinggi yang pernah dicatat oleh sistem dan terdapat tombol Kembali yang mengembalikan pemain ke menu peta.

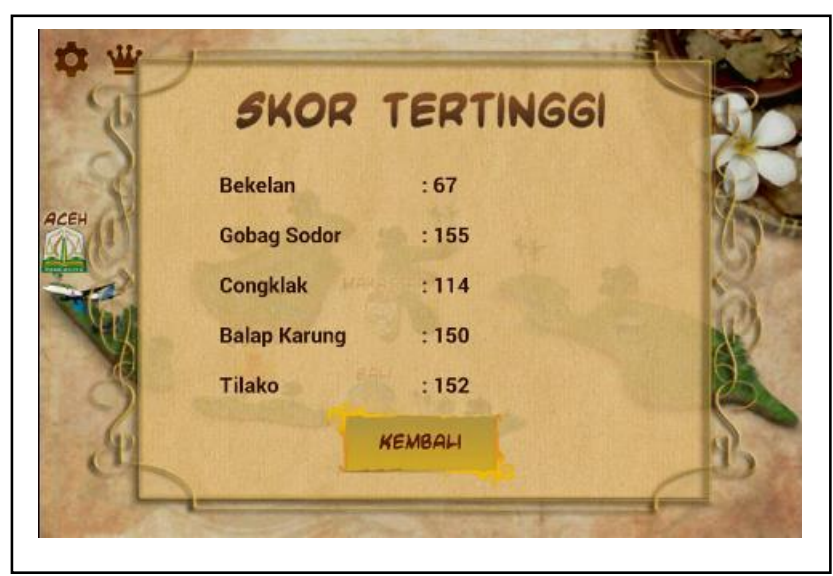

Gambar 9. Halaman Skor

\section{- Halaman Area}

Halaman ini memberikan pilihan cagar budaya yang ada di area tertentu, yang telah dipilih pemain sebelumnya pada menu peta. Untuk tiap tombol yang ditekan akan membuka menu-menu baru mengenai tempat wisata, budaya daerah, atau permainan beserta dengan cara bermain. Terdapat pula tombol kembali untuk kembali ke menu peta.

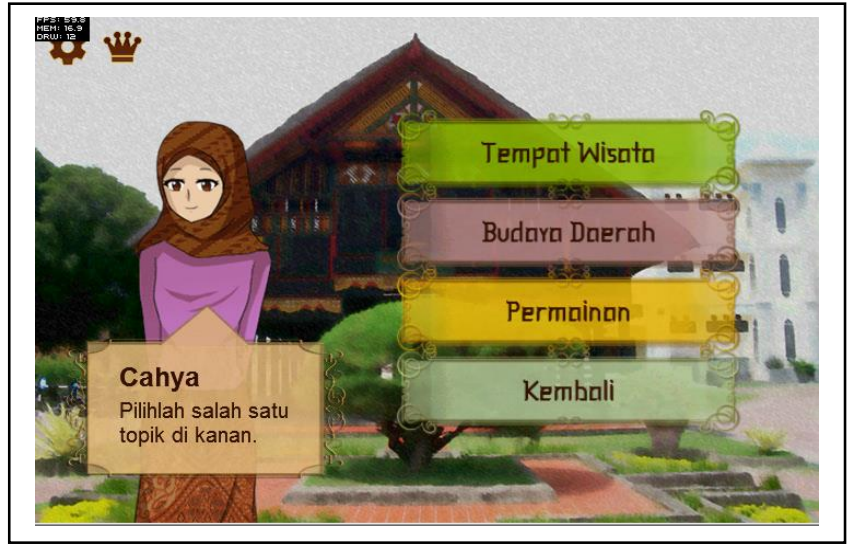

Gambar 10. Halaman Area

- Halaman Skenario

Pada halaman ini pemain menerima informasi mengenai cagar budaya atau budaya area tertentu. Terdapat pula tombol previous dan next yang dapat digunakan untuk melanjutkan atau mengembalikan percakapan.

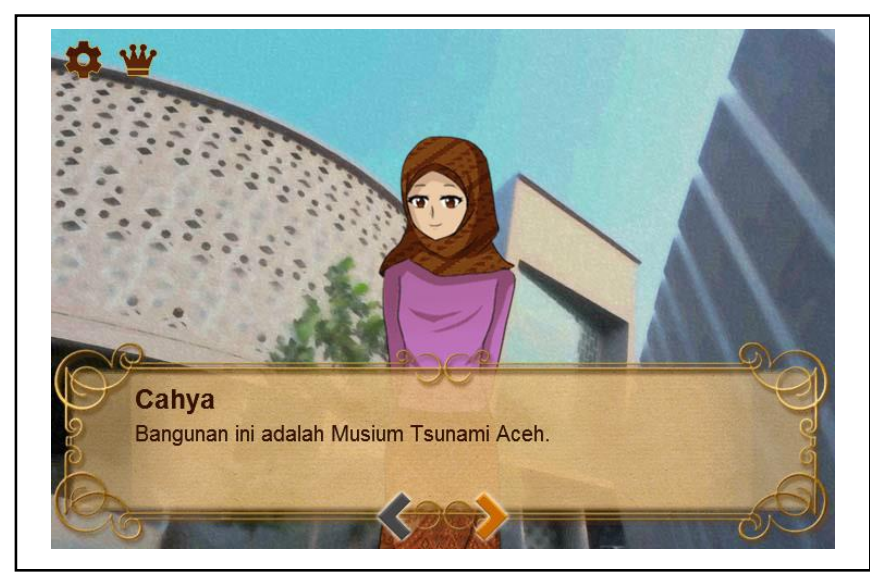

Gambar 11. Halaman Skenario

- Menu Bekelan

Pada menu Bekelan, pemain melakukan touch pada bola bekel untuk melambungkan dan menangkapnya. Setelah itu, pemain mengambil atau memposisikan biji sesuai dengan peraturan set yang ada. Kesalahan pemain akan mengurangi nyawa pemain, dimana jika nyawa telah habis, pemain dinyatakan kalah. 


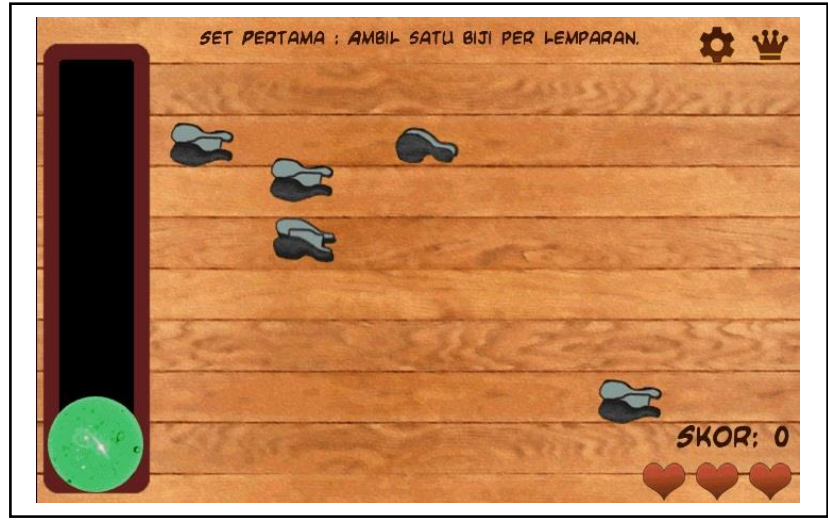

Gambar 12. Menu Bekelan

- Menu Gobag Sodor

Pada menu Gobag Sodor, pemain melakukan swipe pada karakter pemain ke arah yang diinginkan. Pemain harus menginjak garis akhir dan kemudian garis awal untuk menang. Pemain kalah ketika karakter pemain menabrak karakter komputer.

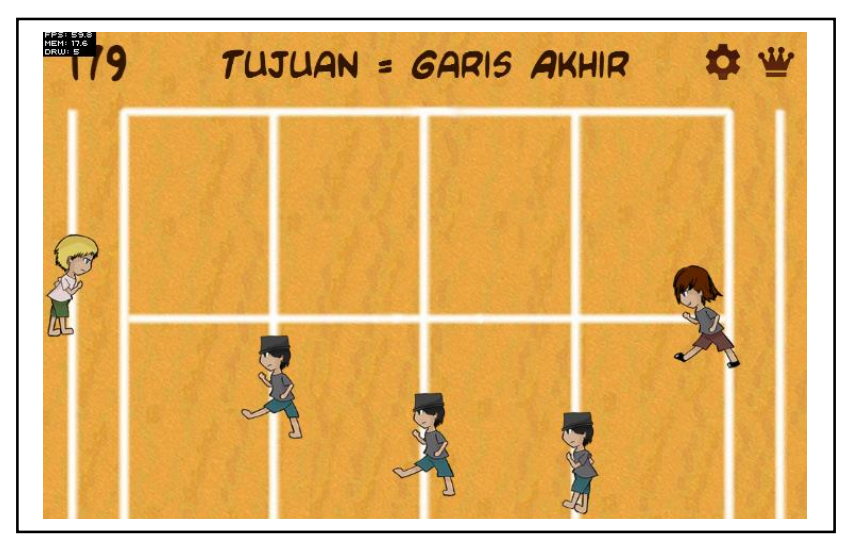

Gambar 13. Menu Gobag Sodor

- Menu Congklak

Pada menu Congklak, pemain harus mendapatkan biji terbanyak untuk menang. Pemain menggunakan fitur touch untuk memilih biji yang hendak dijalankan.

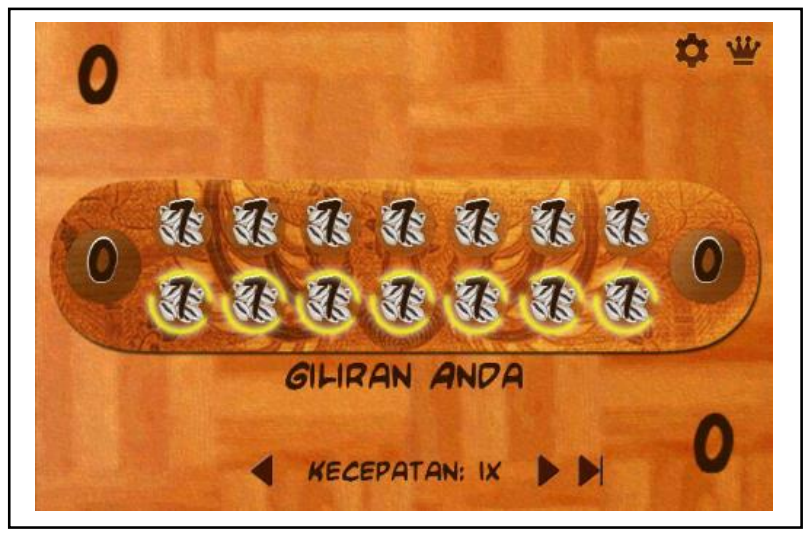

Gambar 14. Menu Congklak
- Menu Balap Karung

Pada menu Balap Karung pemain melakukan fitur touch pada tombol kecepatan untuk menambah bar kecepatan. Jika kecepatan melebihi bar kecepatan maka pemain akan jatuh. Ketika pemain jatuh, pemain dapat melakukan touch pada karakter pemain untuk mempercepat berdiri.

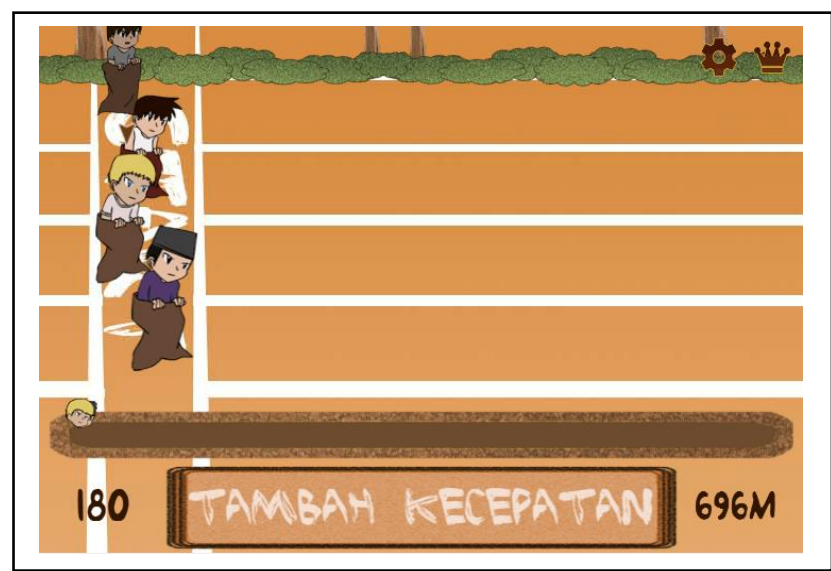

Gambar 15. Menu Balap Karung

- Menu Tilako

Pada menu Tilako pemain melakukan fitur swipe pada bar yang ada di bagian kanan layar untuk menambah kecepatan. Pemain juga menggunakan fitur gyroscope untuk menyeimbangkan bar keseimbangan. Jika bar keseimbangan melewati batas, pemain akan jatuh. Ketika pemain jatuh, pemain dapat melakukan touch pada karakter pemain untuk mempercepat berdiri.

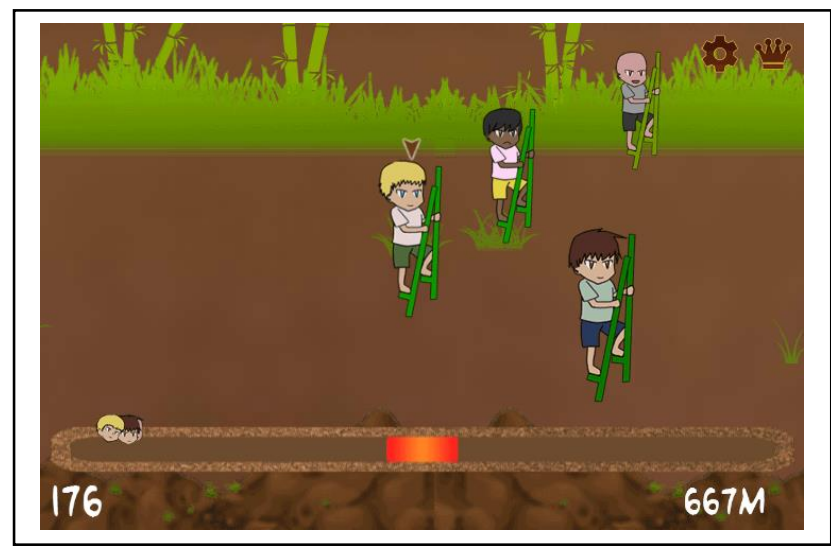

Gambar 16. Menu Tilako

- Menu Menang

Pada saat pemain memenangkan permainan, akan muncul pemberitahuan bahwa pemain telah menang. Ketika pemain menekan layar, pemain akan dikembalikan ke halaman area tempat permainan itu berlangsung. 


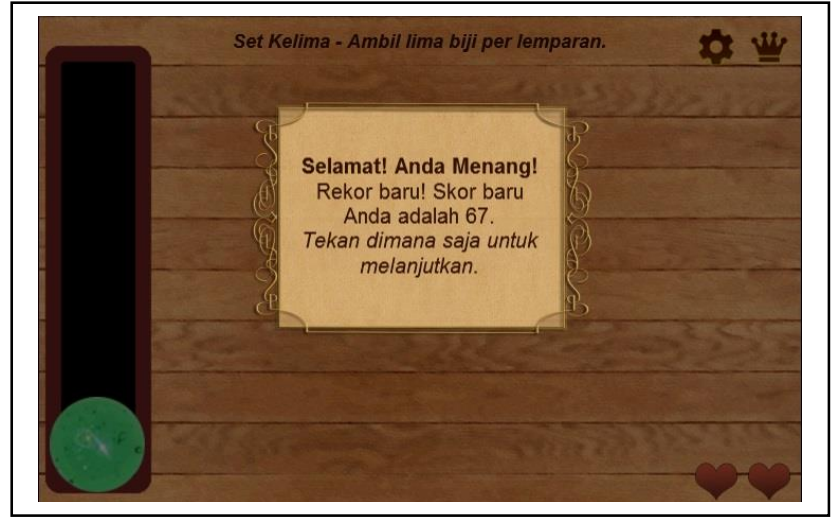

Gambar 17. Menu Menang

- Menu Kalah

Pada saat pemain kalah, akan muncul pemberitahuan bahwa pemain telah kalah beserta pertanyaan jika pemain ingin bermain lagi atau tidak. Ketika pemain menekan tombol Ya, permainan akan diinisialisasi ulang. Ketika pemain menekan tombol Tidak, pemain akan dikembalikan ke halaman area tempat permainan itu berlangsung.

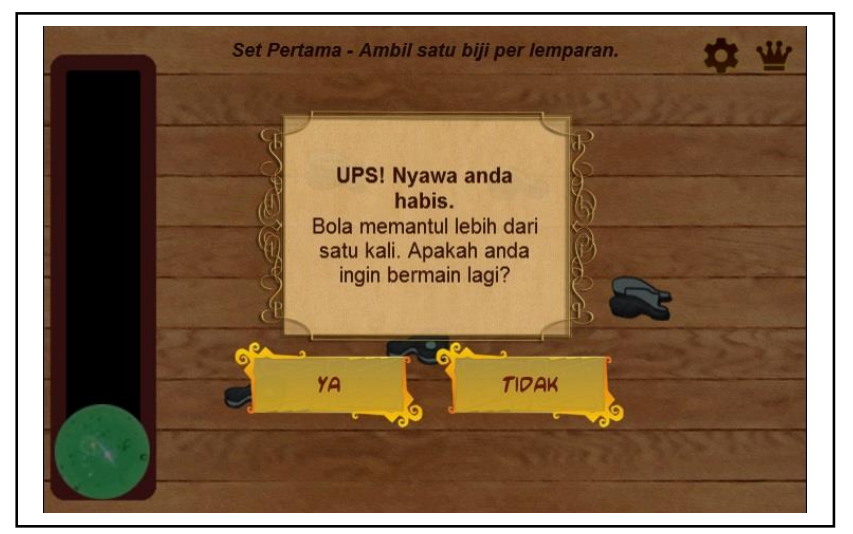

Gambar 18. Menu Kalah

\section{Pengujian}

Aplikasi permainan "Nusantara Indonesia" diuji dengan dua skenario, yaitu pengujian fungsional dan pengujian terhadap pengguna. Pengujian fungsional dilakukan dengan metode black box. Aspek-aspek yang diuji pada pengujian ini meliputi pengujian fungsionalitas pada tiap permainan, pengujian kesalahan, pengujian antarmuka, dan pengujian kasus penggunaan.

Untuk pengujian fungsional, semua skenario pengujian yang dilakukan memberikan hasil yang baik. Hal ini menunjukkan bahwa secara fungsionalitas aplikasi ini telah berjalan seperti yang diharapkan. Pengujian pengguna dilakukan kepada pengguna yang telah memainkan permainan "Nusantara Indonesia" hingga akhir pada perangkat android. Responden berjumlah 30 orang dengan range umur 14-25 tahun. Kuesioner yang diberikan meliputi 4 aspek, yaitu aspek edukatif, aspek permainan, aspek tampilan, dan aspek informasi. Tabel 1 menunjukkan hasil uji coba terhadap pengguna.

Tabel 1. Hasil Uji Coba Pengguna

\begin{tabular}{|c|c|c|c|}
\hline No & Aspek Pengujian & Deskripsi & Persentase \\
\hline 1 & \multirow{2}{*}{ Edukatif } & $\begin{array}{l}\text { Berlaku sebagai sarana } \\
\text { pendidikan }\end{array}$ & $77 \%$ \\
\hline 2 & & $\begin{array}{l}\text { Meningkatkan pengetahuan } \\
\text { mengenai budaya Indonesia }\end{array}$ & $97 \%$ \\
\hline 3 & \multirow{3}{*}{ Permainan } & Menarik untuk dimainkan & $77 \%$ \\
\hline 4 & & Tingkat permainan mudah & $63 \%$ \\
\hline 5 & & $\begin{array}{l}\text { Cara bermain mudah } \\
\text { dipahami }\end{array}$ & $73 \%$ \\
\hline 6 & Tampilan & $\begin{array}{l}\text { Tampilan baik dan mudah } \\
\text { dipahami }\end{array}$ & $77 \%$ \\
\hline 7 & Informasi & $\begin{array}{l}\text { Informasi mengenai budaya } \\
\text { Indonesia mudah dipahami }\end{array}$ & $83 \%$ \\
\hline
\end{tabular}

\section{KESIMPULAN}

Pada bab ini diberikan beberapa kesimpulan yang dapat diambil dari uji coba yang sebelumnya telah dilakukan. Selain itu juga diberikan saran-saran yang bermanfaat dan membangun untuk pengembangan sistem lebih lanjut.

\section{A. Kesimpulan}

Hasil dari penelitian ini dapat disimpulkan sebagai berikut:

1) Agar permainan "Nusantara Indonesia" dapat berjalan pada sistem operasi android maka dibutuhkan framework Starling dengan bantuan program Adobe Flash Builder.

2) Dengan adanya lima pola permainan yang berbeda-beda, permainan "Nusantara Indonesia" menjadi menarik sehingga pemain tidak jenuh saat memainkannya. Hal ini dapat dibuktikan dengan hasil kuesioner yang didukung oleh $77 \%$ responden.

3) Dengan adanya menu tempat wisata dan budaya pada tiap area, permainan "Nusantara Indonesia" dapat menambah khasanah pengetahuan tentang kebudayaan Indonesia bagi para pemainnya. Hal ini dapat dibuktikan dengan hasil kuesioner yang didukung oleh $97 \%$ responden.

B. Saran

Saran yang diterima untuk pengembangan lebih lanjut Permainan "Nusantara Indonesia" adalah:

1. Tutorial permainan lebih baik merupakan interactive step-by-step tutorial.

2. Dapat ditambahkan animasi pada tiap permainan.

3. Penambahan jenis permainan tradisional lainnya.

4. Penambahan pilihan kota-kota yang ada di Indonesia, tidak terbatas pada 4 kota yang telah ada. 


\section{REFERENSI}

[1] Merdekawaty, E. (2006). "Bahasa Indonesia” and languages of Indonesia. Bolzano: UNIBZ - Free University of Bozen.

[2] http://gamua.com/starling/ Diakses: 27 Februari 2015, 02.33
[3] Mulyadi. (2010). Membuat Aplikasi Untuk Android. Yogyakarta: Multimedia Center Publishing.

[4] Suhendar, A. (2002). Visual Modelling Menggunakan UML dan Rational Rose. Bandung: Informatika Bandung 